\title{
SISTEM PENGAMANAN PINTU RUMAH OTOMATIS VIA SMS BERBASIS MIKROKONTROLLER ATMega328P
}

\author{
Muhammad Ridwan Asad ${ }^{1)}$, Okky Dwi Nurhayati ${ }^{2)}$, Eko Didik Widianto ${ }^{2)}$ \\ Jurusan Teknik Sistem Komputer, Fakultas Teknik, Universitas Diponegoro, \\ Jln.Prof. Sudharto, Tembalang, Semarang, Indonesia \\ Email : asadridwan@gmail.com
}

\begin{abstract}
In this final project was designed an automatic door security used SMS, which is serves as security for a microcontroller based door. This system was designed to facilitate the home user to lock the door and notice the condition of the house when the doors was left empty. The medium used is a phone by using SMS facility. This device consists of a sensor that is a "push button" that serves as input to inform the condition of the door to the microcontroller, microcontroller used is ATmega328P. Then Wavecom GSM Modem M1306B which serves as the sender and recipient SMS, using a solenoid to lock the door, and use the buzzer for alarm.

The security system has been built with the working principles if there are people who want to try to enter and then numbers uninitialized on the microcontroller, the system will give a warning SMS notification to the user that "THERE ARE TRYING SIGN", and when the system is forcibly opened, the system will activate alarm as a warning sign and send SMS alert notification text of "alarm" to the phone number programmed into microntroller.
\end{abstract}

Keywords: microcontroller, ATMega328P, Wavecom, Push Button, Buzzer, SMS.

\section{I.PENDAHULUAN}

Perkembangan Ilmu Pengetahuan dan Teknologi (IPTEK) pada saat ini berkembang semakin pesat. Kemajuan ini sangat mempengaruhi pola kehidupan manusia dalam berbagai bidang. Salah satunya adalah penggunaan sistem otomatis pada suatu pekerjaan manusia. Seperti halnya alat pendeteksi gempa, Mobil yang mempunyai banyak sensor untuk tujuan keselamatan, Mobil yang bisa parkir sendiri dan masih banyak sistem otomatis lainnya yang sudah berkembang. Dan antara lain penggunaan teknologi yang sudah berkembang pesat juga adalah penggunaan mobile device yang kini telah menjadi trend masyarakat untuk melakukan kegiatan elektronik, seperti e-banking , e-book serta lainnya.

Perkembangan teknologi ini pun dapat memudahkan manusia untuk mengirimkan data dari jarak jauh dengan keamanan yang sudah terjamin melalui media jaringan internet. Mulai saat ini penggunaan mobile data sangatlah tinggi sehingga menuntut perkembangan yang sangat cepat dari teknologi ini.
Keamanan adalah salah satu bidang pengembangan dari teknologi pengiriman data ini. Sebagai suatu disiplin ilmu, rekayasa teknik pengamanan berfokus pada perangkat, proses dan metode yang dibutuhkan untuk merancang, mengimplementasikan dan menguji sistem, serta mengadaptasi sistem yang ada dengan lingkungannya. Kontrol akses adalah cara untuk membatasi akses ke suatu tempat atau sumber daya lainnya. Penggunaan kontrol akses telah luas digunakan pada sistem pembukaan kunci otomatis, seperti pintu geser otomatis pada gedung-gedung perkantoran yang menggunakan kartu identitas agar pintu bisa terbuka, kartu identitas yang digunakan berisi data unik sebagai kontrol akses pintu. Selama ini sistem pembukaan kunci otomatis umumnya menggunakan kontrol akses fisik, seperti penggunaan tombol dan kartu. Sistem pembukaan kunci otomatis tanpa kontrol akses fisik memungkinkan rancangan yang lebih sederhana, seperti pintu tanpa tuas dan tanpa lubang kunci. Oleh sebab itu diperlukan sistem pengamanan pembukaan kunci otomatis menggunakan metode yang dapat menjadi alternatif dan solusi sistem pembukaan kunci konvensional tanpa menggunakan kontrol akses fisik. Salah satunya adalah dengan metode pengiriman SMS melalui aplikasi android. Sistem pembukaan kunci otomatis menggunakan metode pengiriman SMS melalui aplikasi android adalah konsep autentikasi yang tidak membutuhkan kontrol akses berupa alat fisik. SMS akan digunakan sebagai informasi autentikasi kunci yang akan mengaktifkan sistem pembukaan pintu apakah aktif atau tidak. Sistem pembukaan kunci otomatis menggunakan SMS berbasis aplikasi android dapat menjadi alternatif metode kontrol akses tanpa alat fisik dalam sistem pembukaan kunci otomatis.

\section{Rumusan Masalah}

Berdasarkan latar belakang yang diuraikan di atas, maka permasalahan yang akan dibahas program ini adalah sebagai berikut :

1. Bagaimana merancang suatu sistem yang dapat menggantikan sebuah kunci, sehingga pemilik rumah tidak perlu membawa kunci dan tidak perlu khawatir kunci rumah diduplikasi?

2. Bagaimana menciptakan sebuah sistem pengontrolan pintu otomatis yang dapat diakses dengan jarak yang jauh menggunakan SMS? 
3. Bagaimana merancang pengunci pintu yang otomatis sebagai identifikasi keamanan rumah, sehingga pemilik rumah merasa lebih praktis dalam penggunaannya?

\section{Batasan Masalah}

Agar tidak menyimpang dari permasalah, Tugas Akhir ini memiliki batasan masalah sebagai berikut :

1. Perancangan alat sistem pengamanan dengan menggunakan modem GSM sebagai pengirim dan penerima SMS, serta dengan menggunakan mikrokontroler sebagai kontrol utama.

2. Implementasi pada purwarupa hanya menggunakan 2 pintu.

3. Tidak menggunakan antarmuka pengguna untuk pengaturan sistem.

\section{Tujuan Penelitian}

Adapun tujuan penelitian dari tugas akhir ini adalah sebagai berikut :

1. Sistem pembuka pintu otomatis mampu dikendalikan oleh aplikasi android yang telah disesuaikan sebagai metode kontrol akses.

2. Sistem dapat mengenali dan merespon sms dari nomor yang sudah di simpan pada sistem.

3. Menciptakan sistem penngunci otomatis yang dapat mengetahui keadaan pintu terkunci atau tidak terkunci dan mengunci serta membuka pintu secara otomatis.

4. Mengembangkan suatu aplikasi yang menggunakan SMS untuk mengirimkan data sehingga dapat diakses tanpa menggunakan internet.

\section{DASAR TEORI}

\section{Kunci}

Kunci adalah perangkat mekanik atau elektrik yang dikendalikan oleh suatu objek fisik (seperti kunci, kartu, sidik jari, kartu RFID Radio Frequency Identification Data dan token keamanan) yang berisi informasi rahasia. Kunci umumnya digunakan untuk memungkinkan seseorang mengakses sesuatu yang dilindungi dalam tempat tertentu, sehingga kunci dapat disebut sebagai perangkat kontrol akses. Sistem penguncian pertama ditemukan pada reruntuhan Nineveh, ibukota dari Assyria kuno. Kemudian berkembang ke kunci pin kayu di Mesir, yang terdiri atas baut, pintu dan kunci. Ketika kunci di masukkan, pin di antara pintu terankat dari lubang diantara baut yang memungkinnya untuk bergerak. Ketika kunci dilepas, pin terlepas kedalam baut yang mencegah pergerakan, seperti terlihat pada gambar 1 .

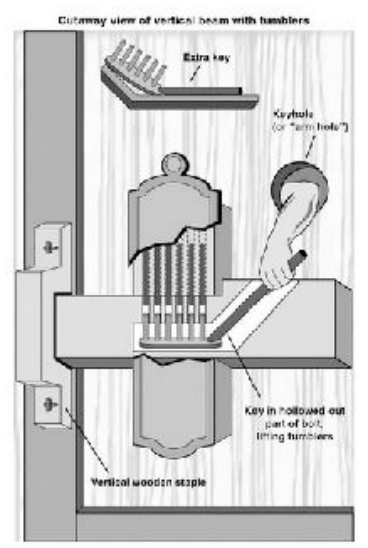

Gambar 1. Kunci Pin Kayu Mesir Kuno

\section{SMS (Short Message Service)}

Teknologi telekomunikasi pada saat ini semakin berkembang, salah satu teknologi telekomunikasi yang sedang berkembang yaitu Short Message Service atau biasanya disebut dengan SMS. SMS adalah kemampuan untuk mengirim dan menerima pesan singkat dalam bentuk teks dari sebuah perangkat nirkabel, yaitu perangkat telekomunikasi telepon seluler, dalam hal ini perangkat nirkabel yang digunakan adalah telepon selular. Teks tersebut bisa terdiri dari kata-kata atau nomor ataupun kombinasi alphanumeric.

Pendapat lain mengenai pengertian SMS diutarakan oleh Romzi Imron (Romzi Imron 2004:1) yang mengungkapkan tentang pengertian SMS adalah sebagai berikut :

"Layanan yang banyak diaplikasikan pada jaringan komunikasi tanpa kabel yang memungkinkan dilakukannya pengiriman pesan dalam bentuk alphanumeric antar terminal pelanggan (Ponsel) atau antara terminal pelanggan dengan sistem eksternal seperti e-mail, paging, voice mail dan sebagainya" (Imron, 2004:1) Gambar 2 menunjukkan cara kerja SMS. 


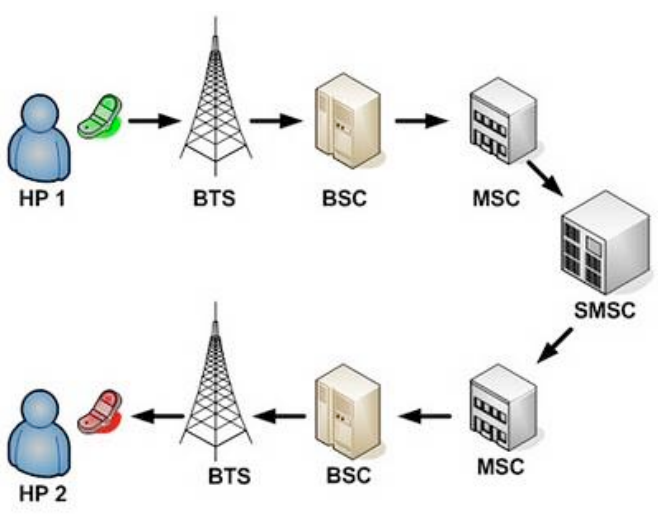

Gambar 2 Cara Kerja SMS

\section{Mikrokontroller ATMega328P}

Mikrokontoler yang diproduksi oleh Atmel. Mikrokontroler ini memiliki 22 pin I/O, semua pin dapat berfungsi sebagai pin I/O digital, 6 pin dapat berfungsi sebagai keluaran PWM dan 6 pin dapat berfungsi sebagai pin I/O analog. Tegangan yang beroperasi untuk mikrokontroler ini adalah 2,7 - 5 Volt. Mikrokontroler ATmega328 memiliki 32 KByte memori flash untuk menyimpan kode sedangkan 2 KByte digunakan untuk bootloader. Mikrokontroler ATmega328 memiliki 2 KByte dari SRAM dan 1 KByte dari EEPROM yang dapat dibaca dan ditulis. Gambar 3 menunjukkan data pin OUT mikrokontroller ATMega328P

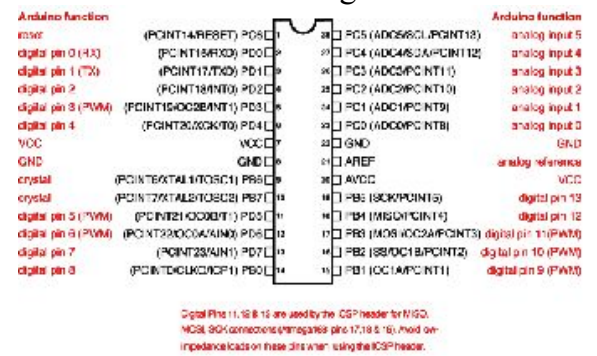

Gambar 3 Mikrokontroller ATMega328P

\subsection{Wavecom M1306B Serial DB9}

Modem GSM adalah sebuah perangkat Modem Wireless Plug and Play dengan konektivitas GSM/GPRS untuk aplikasi-aplikasi machine to machine. GSM Modul atau Modem GSM adalah jenis khusus dari modem yang menerima kartu SIM, dan mengoperasikan selama berlangganan ke operator mobile, seperti ponsel. Modem GSM dihubungkan dengan suatu interface yang memungkinkan aplikasi seperti SMS untuk mengirim dan menerima pesan melalui Modem. Gambar 4 menunjukkan bentuk dari modem wavecom.

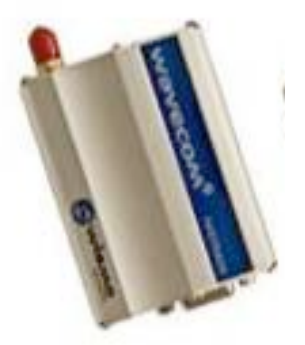

Gambar 4 Modem Wavecom M1306B

\subsection{Kunci Selenoid}

Selenoid adalah salah satu jenis kumparan yang terbuat dari kabel panjang yang dililitkan secara rapat dan dapat diasumsikan bahwa panjangnya lebih besar daripada diameternya. Sedangkan Kunci selenoid adalah gabungan antara kunci dan selenoid dimana biasa digunakan dalam elektronisasi suatu alat sebagai pengunci otomatis dan lain lain nya.

Prinsip selenoid ditemukan oleh fisikawan perancis yang bernama Andre Marie Ampere. Pada bidang rekayaa istilah ini menunjukkan pada perangkat tranduser yang mengkonversi energi ke gerakan linear. Pada saat kumparan dialiri arus litrik maka gaya elektromagnetik akan muncul dan menarik besi yang ada pada bagian tengah kumparan secara linear.

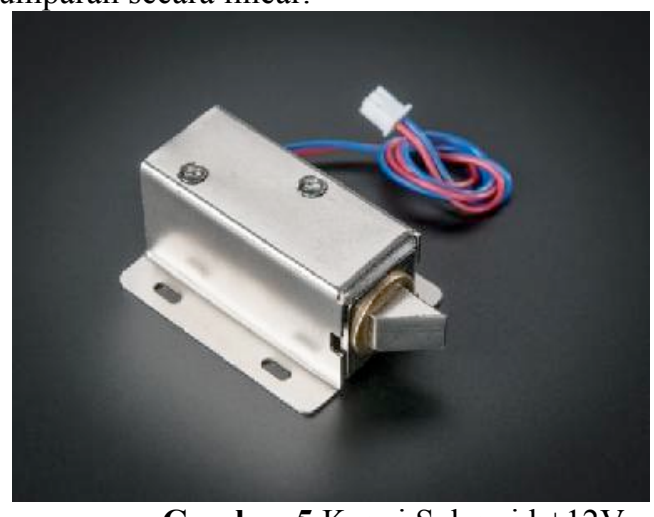

Gambar 5 Kunci Selenoid +12V

\section{SPESIFIKASI DAN PERANCANGAN}

ALAT

\section{Analisis Kebutuhan Fungsional}

Spesifikasi kebutuhan fungsional dilakukan untuk memberi gambaran tentang alat yang akan dibuat dapat berfungsi sesuai dengan yang diinginkan. Kebutuhan fungsional tersebut sebagai berikut:

1. Alat menggunakan mikrokontroller sebagai pusat kontrol untuk mengetahui kondisi pintu. 
2. Alat dapat membaca dan menerima SMS (Short Text Message) untuk digunakan sebagai parameter dalam perintah untuk membuka maupun mengunci pintu.

3. Alat dapat mengirim kondisi awal pintu setelah user melakukan log in pada aplikasi mobile android. Apakah pintu dalam kondisi terkunci atau tidak.

4. Pemberian tombol switch yang digunakan untuk mengunci dan membuka pintu tanpa harus melakukan log in pada aplikasi mobile android ketika user berada pada dalam rumah.

5. Alat ini tidak akan bekerja apabila listrik padam, dan kondisi pintu akan pada kondisi terkunci.

6. Alat ini hanya akan bisa di akses oleh nomor yang sudah diinisialisasikan kepada mikrokontroller. Sehingga untuk keamanan alat ini akan terjaga.

7. Apabila dibuka secara paksa maka alat akan membunyikan alarm dan akan melakukan SMS pemberitahuan terhadap user .

\section{Analisis Non - Fungsional}

Kebutuhan

non-fungsional mendiskripsikan tingkatan dari kualitas. Kebutuhan non-fungsional dari pembuatan tugas akhir ini adalah sebagai berikut :

1. Purwarupa alat dibuat sedemikian rupa sehingga memudahkan dalam proses penggunaan dan pemasangannya.

2. Kontruksi purwarupa alat terbuat dari box plastik agar pengguna dalam melakukan pemasangan dan penambahan komponen tidak terganggu oleh tegangan yang sedang mengalir serta memudahkan untuk membuat semua komponen menjadi satu tempat.

3. Miniatur pintu terbuat oleh kayu.

4. Membutuhkan tegangan listrik ketika ingin menggunakan alat.

5. Menggunakan acrilic untuk membuat tempat pengunci selenoid.

6. Menggunakan lem kayu dan paku untk menyambungkan kayu satu dengan lainnya.

\section{Diagram Blok Alat}

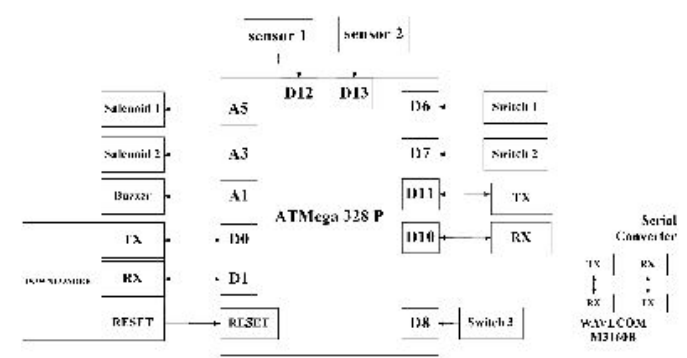

Gambar 6 Diagram Blok Alat

Pada Gambar 6 menunjukkan pin pin yang akan digunakan pada alat. Untuk selenoid menggunakan pin A5 (selenoid1) dan A3 (selenoid2) pada mikrokontroller ATMega328P, yang akan menjadi output dari mikrokontroller.Pin D12 dan D13 digunakan untuk sensor digunakan sebagai masukan pada mikrokontroller. Pin D6, D7 dan D8 digunakan sebagai switch. Pin D10 dan D11 digunakan untuk penghubung antara serial converter dengan mikrokontroller. Pin A1 sebagai buzzer. Pin D0 dan D1 sebagai penghubung antara downloader dengan mikrokontroller.

\section{Perancangan desain papan sirkuit elektronik}

Perancangan papan sirkuit elektronik dibutuhkan untuk menghubungkan komponenkomponen elektronika yang dibutuhkan untuk membuat purwarupa alat.

Papan sirkuit elektronik terlebih dahulu dirancang menggunakan perangkat lunak bernama EAGLE (Easily Applicable Graphical Layout Editor). Gambar 7 menunjukkan desain papan sirkuit utama.

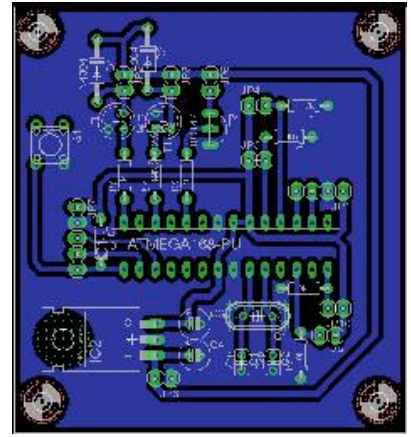

Gambar 7 Desain Papan sirkuit utama

\section{Perancangan Perangkat Lunak}

Perancangan perangkat lunak digunakan untuk memberikan tahapan yang jelas dalam pembuatan program yang akan mengendalikan perangkat keras. Perancangan perangkat lunak ini 
terdiri dari perancangan program utama dimana dalam program perancangan utama sudah mencakup keseluruhan dari kinerja sistem yang diinginkan. Gambar 8 menunjukkan flow chart program utama alat.

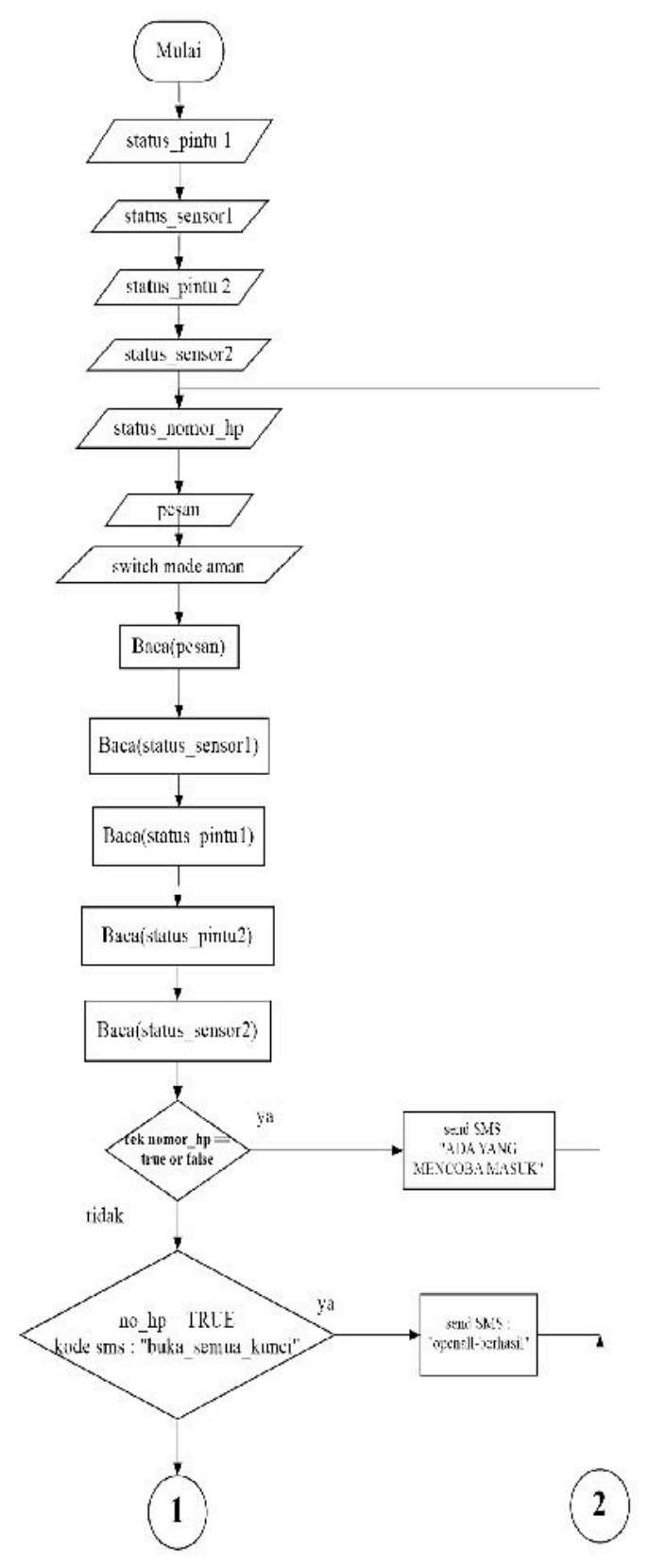

Gambar 8 Diagram Alir Program Utama sistem

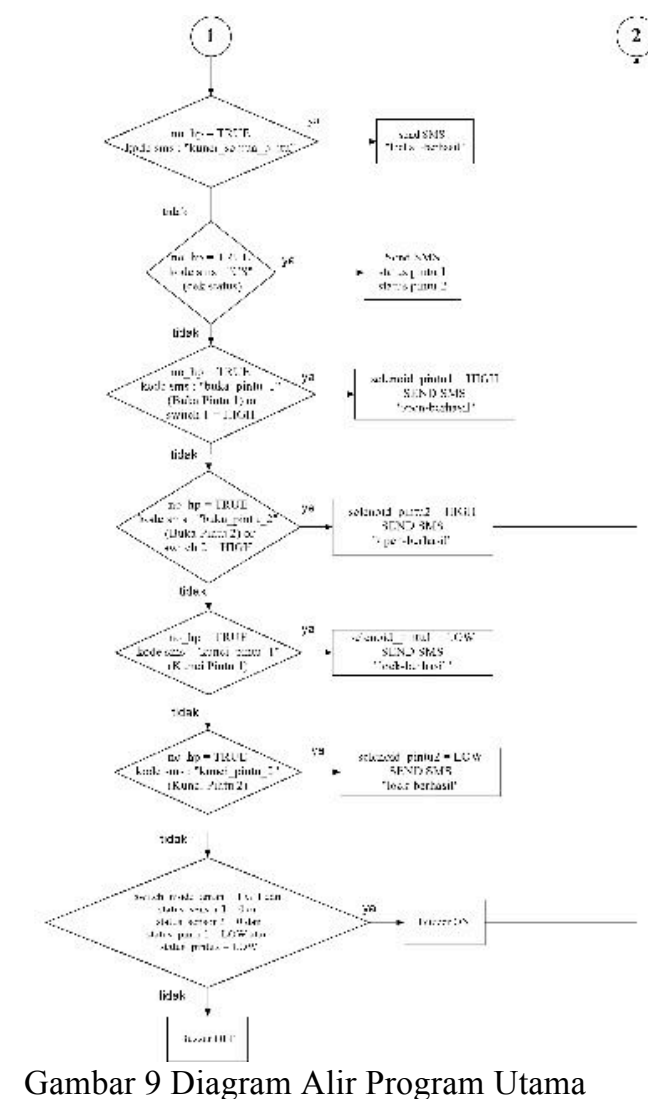

Gambar 9 Diagram Alir Program Utama

\section{IMPLEMENTASI DAN PENGUJIAN}

1. Implementasi Perangkat Keras dan Perangkat Lunak

Perangkat keras yang telah dirancang sebelumnya akan diimplementasikan, mulai dari pembuatan perangkat lunak hingga pemasangan perangkat keseluruhan alat. Hasil implementasi perangkat keras disajikan pada Gambar 10 dibawah ini.

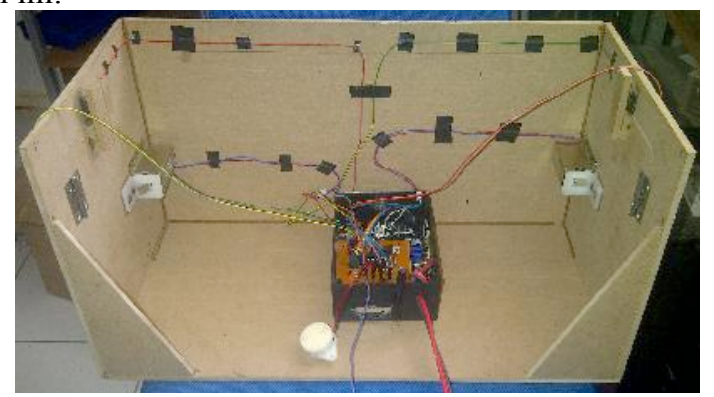

Gambar 10 Implementasi Alat

\section{Pengujian Hubungan Pendek}

Pengujian ini dilakukan untuk mengetahui apakah papan sirkuit mengalami hubungan pendek atau tidak. Pengujian dilakukan dengan cara disambungkan dengan catu daya. Apabila mengalami hubungan singkat dapat 
ditandai dengan LED tidak akan menyala maupun komponen mengeluarkan panas yang berlebihan.

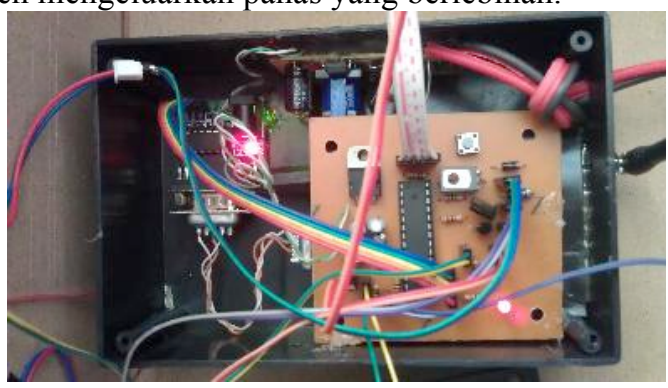

Gambar 11 Pengujian Hubungan Pendek

\section{Pengujian Fungsi Alat}

Pengujian ini bertujuan untuk menguji fungsi fungsi yang telah dirancang. Dimana semua komponen yang berada papan sirkuit utama saling tehubung dan tidak ada jalan yang putus antara komponen yang berhubungan. Serta kondisi awal dari sistem ketika dinyalakan adalah mengunci semua selenoid pada posisi $L O W$.

\section{Pengujian SMS}

Pegujian ini berfungsi untuk mengecek SMS yang diterima, action dan SMS yang dikirimkan oleh mikrokontroller kepada pengguna begitu juga sebaliknya.

\begin{tabular}{l} 
Wavecom selenold doorlock system Wort \\
SenI@00:25 \\
Mo \\
login \\
\hline Wavec om seleno id doorloek system \\
Iogin-berhasil \\
\hline
\end{tabular}

Gambar 12 Perintah login

Wavecomselenoid doorlock system Work] Sent (00:27

\begin{tabular}{|c|c|}
\hline $\mathrm{Me}$ & 00:26 \\
\hline \multicolumn{2}{|l|}{$\checkmark$ check_pintu } \\
\hline $\begin{array}{l}\text { Wavecon seleno id toorlock system } \\
\text { Stale-1,1,0 State-2,1,1 }\end{array}$ & $00: 27$ \\
\hline \multicolumn{2}{|c|}{ Gambar 13 Perintah check_pintu } \\
\hline $\begin{array}{l}\text { Wavecom Selenoid doorlock s } \\
\text { sente 00:26 }\end{array}$ & \\
\hline Iue buka_semua_kunci & $00: 25$ \\
\hline $\begin{array}{l}\text { Wavecem seieno id deorloek system } \\
\text { openalHherhasil }\end{array}$ & 00:26 \\
\hline
\end{tabular}

Gambar 14 Perintah

buka semua kunci

\begin{tabular}{|c|c|}
\hline $\begin{array}{l}\text { Wanceom Selenold dooiloc } \\
\text { Sum egoo:x0 }\end{array}$ & Workd \\
\hline Ke & 00:29 \\
\hline Wavecon Seleno id doerloek systela & $00: 29$ \\
\hline lockall-bemasil & \\
\hline
\end{tabular}

Gambar 14 Perintah

kunci_semua_pintu

\section{V.PENUTUP}

\section{Kesimpulan}

Dari hasil pengujian dan analisis perancangan sistem pengendali pintu otomatis menggunakan aplikasi android melalui media SMS menggunakan ATMega328P (Arduino UNO mikrokontroller) yang dilengkapi dengan Wavecom M1306B dan serial converter, maka dapat diambil kesimpulan sebagai berikut :

1. Alat dapat secara otomatis membuka pintu dan menutup pintu dengan menggunaan perintah SMS yang telah dikirim oleh pengguna.

2. Alat dapat dibuka dan dikunci secara manual menggunakan switch pada setiap pintu.

3. Alat dapat memeriksa keadaan pintu dan keadaan selenoid yang kemudian akan dikirimkan kepada pengguna sebagai notifikasi melalui SMS.

4. Alat dapat mendeteksi dan menerjemahkan perintah yang dikirimkan melaui SMS oleh pengguna.

5. Gagalnya perintah atau notifikasi sering disebabkan karena sinyal yang terganggu atau pulsa yang habis.

6. Keadaan pintu akan mengunci saat tidak ada tegangan dikarenakan pemadaman listrik dikarenakan demi tingkat keamanan ruangan.

\section{Saran}

Berdasarkan pengujian dan analisa terhadap perancangan sistem pengendali pintu otomatis menggunakan aplikasi android melalui media SMS menggunakan ATMega328P (Arduino UNO mikrokontroller) yang dilengkapi dengan Wavecom M1306B dan serial converter yang telah dibuat, alat masih memerlukan penyempurnaan, karena itu diberikan beberapa saran sebagai berikut : 
1. Alat ini masih bisa dikembangkan dari sisi desain maupun komponen yang digunakan.

2. Penambahan Fitur bluetooth untuk membuka dan mengunci pintu secara manual.

3. Penambahan fitur untuk monitoring menggunakan jaringan internet.

4. Dapat dikembangkan pada tahap implementasi dengan menggunakan lebih banyak pintu.

\section{DAFTAR PUSTAKA}

[1] Phillips, Bill, Locks and Locksmithing, McGrawwHill, Inc., New York, 2005.
[2] ATMega328 Microcontroller Data Sheet, www.atmel.com/Images/doc8161.pdf(10/9/14 10.00)

[3] Romzi, Imron, SMS gateway, Bandung, 2004.

[4] Atmel Corporation, Atmel 8-bit AVR Microcontroller with 2/4/8K Bytes In-System Programmable Flash, Atmel, Corp., San Jose, 2013.

[5] Evans, Brian. 2011. Beginning Arduino Programming.

http://it-ebooks.info/book/1474/

$(12 / 9 / 201409.00)$

[6] SerialGSM.h library, https://github.com/meirm/SerialGSM (06/11/2014 10.00)

[7] SMS with the Wavecom WMOi3 GSM Modem and Arduino,

http://nathan.chantrell.net/20130604/sms-withthe-wavecom-wmoi3-gsm-modem-and-arduino/ $(06 / 11 / 201410.00)$ 